\title{
Calando profetisas: gênero e oposição ao montanismo na Ásia Menor do século II d.C.
}

\author{
Silencing prophetesses: gender and opposition to Montanism in \\ $2^{\text {nd }}$ Century Asia Minor
}

\author{
Pedro Luís de Toledo Piza*
}

Resumo: As cristãs Priscila e Maximila iniciaram, na segunda metade do século II d.C., uma atividade de profecia em uma região montanhosa da Frígia, na Ásia Menor, junto a um outro profeta chamado Montano. Assumindo esse ministério, consideravam estar dando seguimento a uma longa tradição de profecia cristã consolidada nessa porção do Império Romano. As tentativas de repressão por parte dos bispos da região, porém, apontam para novos posicionamentos das lideranças cristãs masculinas com relação tanto à profecia em si quanto à possibilidade de mulheres exercerem atividades de autoridade.

\begin{abstract}
The Christian women Priscila and Maximila initiated, in the second half of the second century C.E., a prophetic activity on the hills of Phrygia, in Asia Minor, side by side with another prophet called Montanus. Assuming this ministry, they aimed to give continuity to a long and consolidated tradition of Christian prophecy in this portion of the Roman Empire. The repression attempts by the bishops, however, point to new stances by Christian male leaders relating to two questions: whether prophecy is legitimate in itself and the possibility of women exercising power.
\end{abstract}

Palavras-chave: Montanismo. Lideranças cristãs femininas.

Profecia cristã.

\section{Keywords:}

Montanism.

Female Christian

Leadership.

Christian prophecy.

\footnotetext{
* Mestre e doutorando em História Social pela Universidade de São Paulo (Usp) sob orientação do Prof. Dr. Norberto Luiz Guarinello. Bolsista de doutorado da Fapesp, que financia a pesquisa da qual resultou este artigo.
} 
$\mathrm{P}$ or volta do ano 80, o autor do Evangelho de Mateus compôs ou editou uma série de discursos atribuídos a Jesus de Nazaré. Entre os seus objetivos, aparentemente, estaria fundamentar uma série de normativas para as comunidades cristãs de seu tempo na própria vida e ensinamento daquele que considerava ser o Messias. ${ }^{1}$ Entre elas, se encontrava a necessidade de dar uma boa recepção aos "apóstolos", mas não apenas a eles:

O que vos receber recebe a mim; e o que me recebe está recebendo quem me enviou. O que recebe um profeta em nome de um profeta receberá a recompensa de profeta; e o que recebe uma pessoa justa em nome de uma pessoa justa receberá a recompensa da pessoa justa. E o que der uma taça de água fresca para beber a um desses pequeninos em nome de [ser meu] discípulo, amém vos digo: não perderá a sua recompensa (Mateus 10, 40-41, grifo meu). ${ }^{2}$

O trecho destacado serve de estímulo para que os leitores e/ou ouvintes do texto

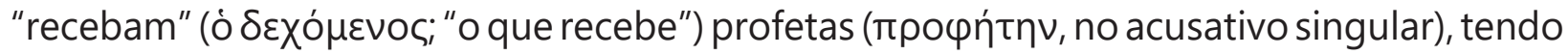
em vista que serão recompensados da mesma forma que estes (muito provavelmente, no final dos tempos). O fato de o texto indicar ao final que mesmo o fornecimento básico de água será recompensado sugere um caráter bem material para essa recepção. Como aponta Viviano (2011, p. 174), o autor aqui está muito provavelmente se referindo a profetas itinerantes de fato e o trecho aparenta refletir a forma como ele enxerga, de forma geral, a estrutura hierárquica de uma comunidade cristã (a sua, talvez, embora essa seja uma afirmação difícil de ser feita tendo por base apenas o texto do evangelho). ${ }^{3}$

No entanto, cerca de um século após o autor dar por terminada sua narrativa, algumas profetisas não estavam sendo tão bem recebidas em comunidades cristãs da Ásia Menor do século II, ou melhor, pelo menos não pelos bispos locais. Entusiasmando o povo local com suas profecias, sofriam a oposição desses homens, os quais aparentemente não reconheciam seu direito à fala, procurando calá-las de várias formas. Acusavam-nas de heresia, embora nunca fossem apresentados os pontos doutrinais nos quais divergiam de sua "ortodoxia". Enfrentando a oposição dos bispos e de alguns pensadores cristãos

\footnotetext{
${ }^{1}$ Viviano (2011, p. 133-4), por exemplo, considera o Evangelho de Mateus um manual, dando direcionamentos de organização e ensino para os líderes de comunidades locais. Já Koester (2005, p. 187) diz que esse texto "explora plenamente o potencial de unificação eclesiástica oferecido pelo gênero do evangelho: a vida, o ensinamento, o ministério e o sofrimento de Jesus devem se tornar o cânon de uma igreja universal".

2 Em geral, as traduções de textos presentes no cânone do Novo Testamento seguirão (por vezes com algumas alterações) a tradução de Lourenço (2017).

${ }^{3}$ A suposição de que seria possível reconstruir a história de comunidades inteiras vinculadas a cada evangelho em específico foi desafiada por Richard Bauckham e outros estudiosos, em Bauckham (1998). A virada teórica de Bauckham na análise dos evangelhos foi usada, por exemplo, por Trebilco (2004, p. 237-241) para descartar o Evangelho de João como fonte-base para a reconstrução histórica do cristianismo em Éfeso na virada dos séculos I e II.
} 
da época, ${ }^{4}$ tiveram seus ensinamentos elencados no rol das correntes consideradas "heterodoxas", sob o epíteto "montanismo".

Por que houve tal oposição a Priscila e Maximila, as referidas profetisas? O que mudou nesse espaço de um século para que lhes fosse negada, da parte dos bispos, até mesmo a taça de água referida pelo Jesus de Mateus? O presente artigo espera apresentar uma resposta plausível para essas questões: aparentemente, a profecia, que era aceita mesmo pelos bispos e inclusive por alguns deles praticada, passou a ser um problema a partir do momento em que serviram para garantir a mulheres a autonomia no ensino e na gestão de recursos da comunidade. A forte reação da parte desses bispos acabou não apenas por excluir de vez as mulheres cristãs de posições de autoridade em suas igrejas, mas também por exilar a própria atividade profética como ministério, o que desencadeou a formação de uma fronteira entre a atividade episcopal e a profecia. Esse era um novo quadro, considerando que essas mesmas funções se viam frequentemente sobrepostas no mesmo indivíduo nas décadas anteriores.

\section{A profecia cristã no primeiro século da Era Cristã}

A profecia executada por Priscila e Maximila na região da Frígia não era uma inovação, apesar do epíteto "Nova Profecia" por ela assumida. Como já visto no início do artigo, o autor do Evangelho de Mateus previa a necessidade de se receber bem os profetas que poderiam aparecer à porta, necessitando de apoio material. No entanto, a profecia cristã não é exatamente uma das principais preocupações do autor, considerando que ele não retorna mais ao tema por todo o restante de sua obra. Se considerarmos que ele fosse um escriba, como sugerem muitos estudiosos, faz sentido que sua atenção estivesse mais voltada ao debate escriturístico com os fariseus que procuravam reorganizar o judaísmo pós-templo do que com o que profetas deviam ou não fazer.

Para entendermos minimamente no que Priscila e Maximila se inspiravam para executar sua profecia e analisar as reações a elas, precisamos trabalhar, ainda que brevemente, com quatro documentos do primeiro século: as cartas autênticas de Paulo, os Atos dos Apóstolos, a Instrução dos Doze Apóstolos e o Apocalipse de João.

Paulo de Tarso lida com a questão da profecia sobretudo na sua primeira carta aos cristãos de Corinto, falando com a autoridade de fundador. ${ }^{5}$ No capítulo 11 , versículos

\footnotetext{
${ }^{4}$ Para um trabalho completo visando a elencar todos os opositores do montanismo do século II ao Vl, ver Tabbernee (2007).

5 "Não sou um apóstolo? Não vi Jesus, Nosso Senhor? Não sois vós a minha obra no Senhor? Se para outros não sou apóstolo, para vós o sou. Pois o selo do meu apostolado no Senhor sois vós" (1Coríntios 9,1-2).
} 
4 e 5, com a mesma autoridade, traça uma normativa para as reuniões de culto que nos é importante:

Todo o homem que reza ou profetiza tendo [algo] na cabeça desonra a sua cabeça. Porém toda a mulher que reza ou profetiza de cabeça descoberta desonra a sua cabeça. Pois é uma e a mesma coisa relativamente a estar [de cabeça] raspada (1Coríntios 11, 4-5).

O primeiro ponto a ser notado aqui é que não parece existir nas comunidades fundadas por Paulo, alguma restrição de gênero na atividade de profecia. ${ }^{6}$ Homens e mulheres têm acesso ao dom, e isso aparentemente não por norma do próprio apóstolo, mas por tradição precedente, como ocorre na condenação do divórcio e nos relatos sobre a Última Ceia e as aparições do Cristo ressuscitado. ${ }^{7}$ No entanto, Paulo hierarquiza as posições de homem e mulher no quesito "vestimenta apropriada". Para ele, o uso do véu pela profetisa é necessário para que fique bem claro a todos os cristãos reunidos que a "mulher é a glória de um homem", enquanto o homem é "imagem e glória de Deus" (1Coríntios 11, 7). Em síntese, mulheres podem executar o segundo maior dom, o qual perde apenas para o dos apóstolos (1Cor 12, 28), e serem responsáveis pela "edificação, exortação e consolação" (1Cor 14, 4) dos membros da assembleia, mas não de forma a se colocar em paridade com os homens.

Ora, esse mesmo pensamento norteou a atividade de Paulo na Ásia Menor, de onde escreveu sua primeira carta aos coríntios. ${ }^{8}$ Sobre sua estadia nessa região não nos dá muitas informações, mas uma narrativa é feita nos Atos dos Apóstolos, ainda que historicamente questionável em muitos pontos. ${ }^{9} \mathrm{O}$ autor não trata de profetas na ocasião da passagem de Paulo pela Ásia Menor, mas os aborda em dois outros pontos da narrativa, não de forma geral, mas sim de modo bem personificado.

O primeiro se dá antes de Paulo (ainda chamado de "Saulo", seu nome hebraico) iniciar suas viagens. Em determinada ocasião, alguns profetas fazem uma viagem de Jerusalém a Antioquia. Um deles, de nome Ágabo, executa uma profecia à moda clássica: prevê "através do Espírito [Santo]" que haveria uma grande fome por "toda a terra", o

\footnotetext{
${ }^{6}$ Que essa profecia signifique "um ministério da palavra derivado de um conhecimento profundo dos mistérios de Deus baseado nas Escrituras", como defende Murphy-O'Connor (2011, p. 474, grifo meu), não se encontra colocado ou indicado em qualquer lugar, seja na primeira carta aos coríntios ou em toda outra documentação elencada no presente artigo.

${ }^{7}$ Cf. p. ex. 1Cor 15, 3: "Proporcionei-vos, em primeiro lugar, o que também eu recebi: que Cristo morreu pelos nossos erros, segundo as Escrituras".

${ }^{8}$ Cf. 1Cor 16, 8-9: "Ficarei em Éfeso até ao Pentecostes. Pois foi aberta para mim uma porta grande e produtiva, ainda que muitos se oponham".

${ }^{9}$ Para uma síntese do debate acerca da confiabilidade de Atos dos Apóstolos e seu uso como fonte de informações acerca de Paulo, ver Dillon (2011, p. 310-311). Para um estudo aprofundado das estratégias literárias utilizadas pelo autor, ver Marguerat (2003).
} 
que viria a se concretizar, segundo o texto, sob o imperador Cláudio (Atos 11, 27-28). Essa profecia tem efeito prático: insta os locais (dentre eles Paulo) a fornecer recursos para que os de Jerusalém não passem necessidade. O profeta Ágabo, portanto, demonstra no mínimo alguma influência na gestão de recursos pela igreja local, mesmo que não seja retratado como um membro permanente dela.

O mesmo Ágabo retorna no segundo momento a ser destacado dos Atos dos Apóstolos. Paulo se encontra em Cesareia Marítima, quando o profeta, descendo da Judeia e lançando mão da teatralidade ${ }^{10}$ anuncia ao apóstolo a sua prisão próxima em Jerusalém, para onde se dirigia. Mais uma vez ocorre a profecia como predição do futuro. No entanto, mais um detalhe é fornecido pelo autor de Atos: Filipe, aquele que servia de anfitrião a Paulo e seus companheiros de viagem, contava com "quatro filhas virgens que profetizavam" (Atos 21, 9). Muitas informações úteis são fornecidas nesse curto trecho, a começar pelo fato de serem mulheres, o que indica uma ausência de restrição de gênero por parte do autor. Além disso, a profecia parece ocorrer regularmente, o que lhes garante a distinção que vale a observação por parte do autor. Por fim, o fato de sua virgindade ser destacada sugere um vínculo dela com a atividade profética. Por outro lado, vale notar que nenhuma das quatro executa a profecia central do trecho, mas sim um homem: Ágabo. Embora nunca o diga tão claramente quanto Paulo, parece haver uma hierarquia de gênero na atividade profética ilustrada pelo autor de Atos. Ágabo tem função ativa e destacada na narrativa, enquanto as filhas de Filipe são meramente mencionadas, como se o autor se visse obrigado a mencioná-las por conta de sua fama, ainda que a contragosto. No fim, acaba sendo sugerido que haja uma fronteira da eficácia: embora estivessem recebendo o apóstolo na casa de seu pai, as virgens profetisas de Cesareia não têm a capacidade de indicar a ele os perigos que o aguardam em Jerusalém. É necessário, mais uma vez, que um homem, Ágabo, entre em cena para alertar Paulo com a autoridade do Espírito Santo.

O terceiro documento do século I que aborda a atividade profética é a Instrução dos Doze Apóstolos, também conhecida pela transliteração de sua primeira palavra, Didakhe. Apesar de sua datação ser debatida, grande parte dos estudiosos coloca sua composição, ao menos em parte, ainda no primeiro século da Era Cristã. ${ }^{11}$ Apresentandose como um texto traçando os principais ensinamentos e normas da parte dos doze apóstolos, o documento reúne uma série de instruções sobre os profetas e como agir

\footnotetext{
${ }^{10}$ Retirando de Paulo o cinto, usa-o para atar os próprios pés e mãos de modo a indicar o que viria a ocorrer com seu dono. Cf. Atos 21,11. Dillon (2011, p. 382) compara a teatralidade de Ágabo nesse relato à dos profetas dos reinos de Israel e Judá.

${ }^{11}$ Koester (2005, p. 174) considera que a forma final do documento pertence ao século II, mas com "materiais preciosos do século I". Milavec (2003, p. 41) exclui uma autoria por parte dos doze apóstolos de Jesus.
} 
perante um. Dentre as muitas normas (cujo estudo completo valeria um artigo à parte) relativas a esse grupo, encontra-se a proibição de interromper e/ou questionar o profeta enquanto ele está falando, embora seja recomendada uma série de testes para verificação da confiabilidade do profeta por suas atitudes (Didakhe 11, 7-12). O profeta, por exemplo, não deve pedir dinheiro para si, embora a Instrução estabeleça que um salário Ihe seja pago pelos fiéis locais (Did., 13, 3). Realçado como sumo sacerdote, ${ }^{12}$ ele parece exercer uma função fundamental na oração comum (Did., 10, 7). Em suma, a Instrução apresenta um modelo de igreja em que o profeta exerce uma função fundamental no culto, inclusive recebendo um salário gordo para tanto. Daí, provavelmente, a preocupação do autor (ou dos autores, não sabemos) em impedir que fraudulentos e estelionatários possam exercer atividade tão importante.

O quarto e último documento, o Apocalipse de João, é de suma importância, uma vez que a maioria dos estudiosos o considera obra de um profeta, João de Patmos (KOESTER, 2005, p. 269; YARBRO COLLINS, 2011, p. 838). Uma vez mais, estamos restritos a fazer uma análise breve de um documento que bem vale uma tese. No entanto, alguns pontos serão suficientes como insumo para pensar o montanismo na Ásia Menor, região esta que contava com as sete igrejas às quais João se dirige, ou melhor, o "Espírito" de Cristo através dele (Apocalipse de João 2, 7, 11, 17, 29; 3, 6, 13, 22): "Quem tem ouvido que ouça aquilo que o espírito diz às congregações". Em primeiro lugar, é necessário notar a autoridade que a "revelação" (Apoc., 1, 1) por parte do Cristo ressuscitado, poderoso e terrível é manejada pelo autor na medida em que exorta e adverte as igrejas acerca de questões do cotidiano: ${ }^{13}$ carnes sacrificadas aos ídolos devem ser desprezadas pelos fiéis; os que não as desprezam, devem ser excluídos da convivência comum; caso sejam nicolaítas, a condenação é ainda maior, pois são "odiados" pelo Cristo, que não os suporta. Em um momento de aparente urgência escatológica, ainda reforçada por possíveis perseguições locais, é provável que a autoridade do discurso do profeta João se visse igualmente realçada, principalmente se ele estivesse cumprindo alguma pena no momento em que escrevia, como parece sugerir. ${ }^{14}$ No entanto, sua autoridade não existia sem oposição. Escrevendo aos cristãos de Tiatira, João condena de forma brutal uma profetisa que the parecia rivalizar em influência nessa cidade:

\footnotetext{
12 Milavec (2003, p. 75) vincula a nomeação, pelo autor, dos profetas como sumo sacerdotes e os benefícios financeiros que recebem a uma posição "anti-Templo" de um cristianismo ainda muito vinculado ao ambiente judaico.

${ }^{13}$ Acerca da violência como marca da masculinidade do Cristo representado no Apocalipse de João, cf. Conway (2008, p. 159-174).

${ }^{14}$ Collins (2010, p. 386) defende que a extrema urgência escatológica da apocalíptica cristã do primeiro século, em que o Messias esperado já veio e vive-se em pleno fim do mundo, garantia aos profetas uma autoridade singular, a ponto de João abrir mão do tradicional uso de pseudônimos, como ocorria nos apocalipses judaicos.
} 
Mas tenho [isso] contra ti, porque perdoas a mulher Jezabel, que se afirma profetisa e ensina e desvia os meus escravos, [levando-os] a fornicar e a comer carnes imoladas a ídolos. E eu the dei tempo para que ela se arrependesse, mas não quer arrepender-se da sua fornicação. Eis que a lanço para uma cama e [lanço] os que com ela cometeram adultério para uma grande aflição, e eles não se arrependerem das obras dela, e os filhos dela eu matarei com morte (Apoc., 2, 20-23).

Alguns pontos precisam ser destacados de um trecho tão violento. Primeiramente, existe uma mulher profetizando em Tiatira. Por mais que João não queira reconhecerIhe como profetisa ("[...] que se afirma profetisa [...]"), ela parece gozar de aceitação considerável nessa cidade a ponto de incitá-lo a profetizar a morte de seus "filhos", muito provavelmente querendo referir-se a seus discípulos. Em segundo lugar, a brutalidade do profeta o leva a usar as formas de desqualificação de cunho sexual contra sua adversária, ${ }^{15}$ inclusive cunhando-Ihe o insultuoso nome de "Jezabel", a infame inimiga bíblica do profeta Elias. Aqui, temos um primeiro caso de um homem procurando colocar uma profetisa "em seu devido lugar". Ainda assim, vale notar que este homem é também ele profeta, nunca executando tal desmoralização em nome próprio, mas sim do Cristo apocalíptico, de cuja boca sai uma espada de dois gumes e cuja túnica conta com uma barra ensopada de sangue de inimigos (Apoc., 19, 12-13, 15). Tudo aqui é violência divinamente autorizada na figura do profeta.

\section{O caso de Priscila e Maximila}

Quando Priscila e Maximila iniciaram sua atividade junto a Montano na região montanhosa do noroeste da Frígia, ${ }^{16}$ a profecia era um fenômeno assentado no cristianismo da Ásia Menor. Milcíades, um dos opositores contemporâneos à "Nova Profecia", elenca entre os profetas da região certa Amia de Filadélfia, além de outro profeta chamado Quadrato. ${ }^{17}$ Ao fim do século II, Polícrates, bispo de Éfeso, dá destaque à presença de duas das filhas de Filipe citadas nos Atos dos Apóstolos, na Frígia. ${ }^{18}$ Ao contrário do que parte da historiografia defende, não havia necessariamente uma relação de contradição

\footnotetext{
${ }^{15}$ A violência de gênero presente nesses ataques consegue ficar, segundo Conway (2008, p. 163), em uma posição bem marginal mesmo do ideal de masculinidade greco-romano.

${ }^{16}$ Um autor anônimo citado por Eusébio de Cesareia na História Eclesiástica $(V, 16,7)$ situa em Ardabau, Mísia, nos limites da Frígia, o primeiro local de atividade de Montano. Van Dam (2008, p. 326) vincula o surgimento e rápida difusão do montanismo nessa região montanhosa e rural à sobrevivência de tipos de cristianismo resistentes aos modelos presentes nas regiões mais urbanizadas.

${ }^{17} \mathrm{Cf}$. Eus., Hist. Eccl., V, 17, 3. Todos os autores aqui citados tiveram fragmentos de suas obras conservados por serem citados pelo bispo historiador.

${ }^{18} \mathrm{Cf}$. Eus., Hist. Eccl., V, 24, 2. Elas também são lembradas por Milcíades em V, 17, 3.
} 
entre o ministério ascendente dos bispos e o da profecia. ${ }^{19}$ Nesse caso, as fronteiras sociais que demarcavam um e outro ofício não raro eram negociáveis e se sobrepunham com certa frequência. É possível que, em Éfeso, na virada dos séculos I e II, profetas tivessem parte ativa no ato de imposição das mãos (ou mesmo na própria escolha) de novos bispos, a julgar pela pseudoepígrafa Primeira Carta de Paulo a Timóteo. ${ }^{20}$ Bispos profetizarem não era algo raro de se ver. Quando Inácio de Antioquia passa por Filadélfia, ele profetiza a necessidade de união dos cristãos locais em torno de bispo, presbíteros e diáconos, mesmo que seus ouvintes desconfiem da origem sobrenatural de sua fala em específico. ${ }^{21}$ Policarpo, bispo de Esmirna, é chamado "mestre apostólico e profético" (Eusébio de Cesareia, História Eclesiástica IV, 15, 39) pelo(s) autor(es) da narrativa de seu martírio, o que parece ser confirmado pelo mesmo profetizar, a partir de uma visão, a sua própria morte e como ela deveria ocorrer (Eus., Hist. Eccl., IV, 15, 10). Do mesmo modo, Melitão, bispo de Sardes por essa época, era conhecido como autor de profecias.22

No entanto, algo de novo ocorre na reação ao montanismo. Não é, inicialmente, uma rejeição à profecia em si. Como é usual nesse caso, temos, em geral, apenas a pena dos opositores. ${ }^{23}$ Um deles, um anônimo citado por Eusébio de Cesareia, na sua História Eclesiástica $(\mathrm{V}, 16,7)$, afirma que a maneira de Montano profetizar é "inteiramente oposta ao uso tradicional conservado pela antiga tradição da Igreja", embora não especifique onde ocorre propriamente a transgressão a essa norma comum que desconhecemos. Comentadores também já notaram que o montanismo é muito artificialmente enquadrado como heresia pelos seus próprios detratores, uma vez que nenhum ponto doutrinal específico serve de pomo da discórdia no conflito (MARJANEN, 2008, p. 195).

Ainda assim, as tentativas de bispos e presbíteros de fazer as profetisas se calarem são frequentes e reiteradas. O fato de tal atitude ser noticiada unicamente em relação às mulheres deve ser enfatizado. Nas três citações de textos contemporâneos ao início da Nova Profecia feitas por Eusébio, nunca são homens, como o próprio Montano e certo Temisão, que sofrem a tentativa de censura. A primeira citação é do autor anônimo já referido:

\footnotetext{
${ }^{19}$ Como exemplo dessa perspectiva, temos Marjanen (2008, p. 185).

${ }^{20}$ Cf. 1 Timóteo 1, 18; 4, 14, que referem profecias preditas a respeito de Timóteo no ato de receber a imposição das mãos. Trebilco (2004, p. 460-461) vê aqui a participação de profetas nas escolhas para liderança das comunidades de Éfeso refletidas em 1 e 2 Timóteo.

${ }^{21}$ Inácio de Antioquia descreve sua profecia e a desconfiança de parte de seus ouvintes em Filadelfienses 7.

22 Que Melitão poderia ser também profeta, além de bispo, parece ser sugerido por Polícrates de Éfeso, o qual afirma ter ele vivido "plenamente no Espírito Santo" (Eus. Hist. Eccl., V, 23, 5), algo semelhante ao que diz acerca das filhas de Filipe. Sobre Melitão de Sardes ter sido de fato um profeta e um possível opositor do montanismo, conferir Tabbernee (2007, p. 25-7).

${ }^{23}$ Não convém aqui usarmos Tertuliano de Cartago, uma vez que se trata de autor que se encontra longe da região analisada aqui e ainda em um período posterior, já no começo do séc. III.
} 
E não diga na mesma obra (de Astério Urbano) o espírito que fala por Maximila: 'Como lobo fui perseguido, para longe do rebanho. Não sou lobo; sou palavra, espírito, poder'. [...] Pelo espírito obrigue a confessá-lo aqueles que estavam presentes para examinar o espírito que falava e para discutir com ele: homens experimentados e bispos, Zótico da aldeia de Comana e Juliano de Apameia, aos quais os companheiros de Temisão fecharam a boca, impedindo que refutassem $o$ espírito mentiroso e sedutor do povo (Eus., Hist. Eccl., V, 16, 17, grifos meus).

O segundo momento, vindo de uma obra do bispo Apolinário de Hierápolis contra o montanismo, não se encontra citado ipsis literis por Eusébio, mas é por ele mencionado indiretamente: "[Apolinário] diz ainda que Zótico, citado pelo escritor [anônimo] precedente, sobrevindo quando Maximila simulava profetizar em Pepuza, tentou confundir o espírito nela atuante, mas pelos sequazes desta viu-se impedido" (Eus., Hist. Eccl., V, 18, 13, grifo meu). O terceiro momento envolve uma tentativa de exorcismo e encontra-se ao final de uma carta conjunta de Serapião de Antioquia e outros bispos com ele reunidos: "Pelo Deus vivo, que está nos céus, o bem-aventurado Sotas de Aquiale quis expulsar o demônio que se apossara de Priscila, e os hipócritas não lho permitiram" (Eus., Hist. Eccl., V, 19, 3).

Convém, nesse ponto, destacar que, se a Instrução dos Doze Apóstolos constituía parte do que o autor anônimo definiu como "uso tradicional conservado pela antiga tradição da Igreja" acerca da profecia ou o representava minimamente, quem se encontrava em franca dissonância com a tradição eram os próprios bispos. De fato, como já referimos, a Instrução proíbe terminantemente que um profeta ou uma profetisa seja interrompido(a) ou mesmo julgado(a) em suas palavras, ${ }^{24}$ fazê-lo seria um pecado sem perdão (Did., 11, 7). Para testar um profeta ou profetisa, era necessário contar apenas com o julgamento de suas atitudes cotidianas ou no momento do culto, de modo a nunca correr o risco de altercar com o espírito presente nele ou nela. Vendo por esse ponto, é compreensível a reação constante do povo quando Priscila e Maximila eram interrompidas: mesmo que fossem bispos, eles não tinham o direito de "discutir" ou debater com o "Paráclito" presente nelas, muito menos de tentar exorcizá-lo de seus corpos, uma verdadeira blasfêmia. Nem sequer o fato de elas e Montano falarem como o Paráclito na primeira pessoa poderia ser acusado de inovação, uma vez que João de Patmos faz exatamente o mesmo ao admoestar e advertir comunidades inteiras pela voz do Cristo ressuscitado, como já visto também.

Por que, então, tamanha oposição por parte dos bispos da Ásia Menor, a ponto de transgredir as antigas normas de tratamento destinado às profetisas? Talvez uma resposta

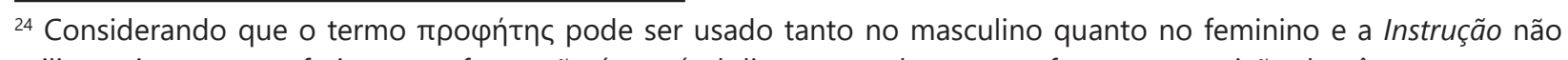
utiliza artigos ao se referir aos profetas, não é possível dizer que o documento faça uma restrição de gênero. 
plausível possa ser retirada da descrição que o autor anônimo faz da profecia de Maximila e Priscila:

\begin{abstract}
Suscitou ainda duas mulheres, repletas de um espírito bastardo, que se puseram a falar insensatamente e a contratempo, de modo estranho, semelhante a ele [Montano?]. Este espírito proclamava bem-aventurados os que se alegrassem com ele e dele se gloriassem e ensoberbecia-os através da grandeza de suas promessas. Por vezes também fazia-Ihes censuras muito justas e dignas de crédito, a fim de mostrar-se capaz de repreender; mas poucos eram os frígios que se iludiam. O espírito de arrogância ensinava ainda a blasfemar contra a Igreja universal, difundida sob o céu, porque não honrava sua falsa profecia, que nela nem tinha acesso (Eus., Hist. Eccl., V, 16, 9, grifos meus).
\end{abstract}

É possível que as duas profetisas, a partir do trecho destacado, estivessem profetizando coisas como: "Arrepende-te. Se não [o fizeres], venho encontrar contigo depressa e Ihes farei guerra com a espada da minha boca" (Apoc., 2, 16). Ou talvez: "Conheço as tuas obras [e sei] que tens nome [e sei] que vives - e [porém] estás morto" (Apoc., 3, 1). E ainda: "Porque dizes que 'sou rico' e 'enriqueci' e 'não preciso de nada'; e não sabes que tu és o desgraçado e miserável e mendigo e cego e nu" (Apoc., 3, 17). Assim como João de Patmos, Maximila e Priscila fundamentavam sua autoridade na extrema urgência escatológica: se a apocalíptica judaica era fundamentada na espera angustiante pelo Messias que traria o fim do mundo conhecido, a cristã já vivia nos dias do Messias. Seu retorno era iminente e a atividade profética era necessária para que os fiéis fossem guiados em sua atitude, estando na soleira do fim dos tempos.

No entanto, Priscila e Maximila são rejeitadas com formas de desqualificação de cunho sexual que bem lembram aquelas dirigidas por João de Patmos à profetisa "Jezabel". ${ }^{25}$ Agora, porém, não se trata mais de disputa entre dois profetas, mas da reação de bispos às profecias de duas mulheres. Tudo indica que o problema de fundo é de gênero. Por mais que Montano seja citado pelas fontes de Eusébio como o iniciador da Nova Profecia, fica claro pelas fontes que ele e Temisão são com frequência esquecidos diante das polêmicas envolvendo Priscila e Maximila. Parece ser intolerável ao autor anônimo, a Milcíades e a Sotas de Aquiale, dentre outros, que bispos tivessem de ouvir admoestações, exortações e advertências dirigidas a eles pela boca de mulheres, mesmo sendo justas, como visto na citação acima. Semelhante situação contrariava frontalmente a Primeira Carta a Timóteo $(2,12)$, que definia expressamente: "Não admito à mulher que ensine, nem que exerça domínio sobre o homem; mas sim que se mantenha em silêncio".

${ }^{25}$ Priscila, por exemplo, tem sua virgindade questionada, sendo acusada de ter abandonado seu marido (Eus., Hist. Eccl., $\mathrm{V}, 18,3)$. 
Na verdade, a crise em torno da atividade de Maximila e Priscila parece ser o ponto culminante de uma longa tensão de gênero na definição das fronteiras sociais da atividade profética cristã. Se a Instrução dos Doze Apóstolos não faz qualquer distinção e/ou hierarquização de gênero na profecia, temos um Paulo de Tarso já incomodado que homens e mulheres pudessem ser vistos como iguais ao profetizarem. Tal tensão se reflete também no realce dado a Ágabo, nos Atos dos Apóstolos, em detrimento das filhas de Filipe. No Apocalipse de João, a violência de gênero explode pela pena brutal do profeta João. Se considerarmos, com Stewart-Sykes (2001), que a profecia cristã nunca se encontrava desconectada do ambiente doméstico no qual se dava o culto (um ambiente eminentemente patriarcal na Ásia Menor da época), a tensão de gênero ganhava conotações especiais: a centralidade do bispo patriarcal em ascensão se encontrava em perigo. Mesmo que esses bispos pudessem profetizar, seria a palavra de um inspirado contra outro. Quem estaria certo?

Ao que tudo indica, a resposta organizada dos bispos da Ásia Menor e da Síria (os primeiros sínodos parecem ocorrer então) transcendeu a questão de gênero, ${ }^{26}$ mesmo que tivesse sido por ela inflamada. A profecia deixou de ser encarada como uma atividade legítima a partir de então, pois toda e qualquer pessoa que se dissesse inspirada pelo Espírito Santo a dar ordens e admoestar seria suspeita de "montanismo". Algo semelhante ocorre na ambiguidade da situação de Tertuliano de Cartago, já no século III, após este abraçar a Nova Profecia: não se considera, aparentemente, em cisma com a lgreja que adotara anteriormente, uma vez que não defendia nenhuma heresia, mas não podia esconder seu desprezo pelos "corporais", especialmente os bispos (REBILLARD, 2008, p. 306-7).

\section{Conclusão}

Inflamada, ao que tudo indica, por uma questão de gênero, a Nova Profecia levou a uma redefinição de fronteiras sociais por parte dos bispos da Ásia Menor. Quando Polícrates de Éfeso elenca as principais personalidades de sua região, as filhas de Filipe e Melitão de Sardes serão referidos apenas como pessoas que viveram "sob o Espírito", mas não claramente como profetas e profetisas (Eus., Hist. Eccl., V, 24, 2-5). A profecia tornou-se característica do montanismo, enquanto os bispos fundamentariam sua autoridade unicamente nos apóstolos dos quais se diziam sucessores. E tudo se

\footnotetext{
${ }^{26}$ A primeira reunião de bispos relatada por Eusébio de Cesareia (Hist. Eccl., V, 19, 1-4, 1QA) se dá como resposta ao montanismo, saindo dela a carta escrita por Serapião de Antioquia e assinada por outros bispos, a qual já foi citada no artigo.
} 
deu, aparentemente, pela recusa em ouvir o que as profetisas Maximila e Priscila tinham a dizer, ou melhor, o que o Paráclito queria dizer-lhes. A solução foi drástica, mas, para quem se propunha a defender um status quo eminentemente patriarcal na comunidade cristã, não poderia ser acusada de desarrazoada. De fato, indícios apontam para a adoção paulatina, por parte da Nova Profecia, de uma hierarquia semelhante à da Igreja "católica", mas com o diferencial de ter as posições hierarquicamente superiores ocupáveis por mulheres (TORJESEN, 2008, p. 395).

\section{Referências}

\section{Documentação textual}

ANÔNIMO. Didakhé. Translated by Aaron Milavec. Collegeville: Liturgical Press, 2003.

EUSEBIUS OF CAESAREA. The Ecclesiastical History. Translated by J. E. L. Oulton. London: William Heinemann, 1942.

IGNATIUS OF ANTIOCH. Letters. Translated by William Schoedel. Philadelphia: Fortress Press, 1985.

NOVO TESTAMENTO: os quatro evangelhos. Traduzidos por Frederico Lourenço. São Paulo: Companhia das Letras, 2017.

NOVO TESTAMENTO: Apóstolos, Epístolas, Apocalipse. Traduzidos por Frederico Lourenço. São Paulo: Companhia das Letras, 2017.

\section{Obras de apoio}

BAUCKHAM, R. (ed.). The Gospels for all Christians: rethinking the Gospel audiences. Grand Rapids: William B. Erdmans, 1998.

COLLINS, J. J. A imaginação apocalíptica: uma introdução à literatura apocalíptica judaica. São Paulo: Paulus, 2010.

DILLON, R. J. Atos dos Apóstolos. In: BROW, R. E.; FITZMYER, J. A.; MURPHY, R. E. (org.). Novo comentário bíblico São Jerônimo: Novo Testamento e artigos sistemáticos. São Paulo: Paulus, 2011, p. 309-398.

KOESTER, H. Introdução ao Novo Testamento: História e literatura do cristianismo primitivo. São Paulo: Paulus, 2005. v. 2.

MARGUERAT, D. A primeira história do cristianismo: os Atos dos Apóstolos. São Paulo: Paulus, 2003. 
MARJANEN, A. Montanism: egalitarian ecstatic "New Prophecy". In: MARJANEN, A.; LUOMANEN, P. (ed.). A companion to second-century Christian 'heretics'. Leiden: Brill, 2008, p. 185-212.

MURPHY-O'CONNOR, J. Primeira Carta aos Coríntios. In: BROWN, R. E.; FITZMYER, J. A.; MURPHY, R. E. (org). Novo comentário bíblico São Jerônimo: Novo Testamento e artigos sistemáticos. São Paulo: Paulus, 2011, p. 453-486.

REBILLARD, É. The West (2): North Africa. In: HARVEY, S. A.; HUNTER, D. G. (ed.). The Oxford Handbook of Early Christian Studies. Oxford: Oxford University Press, 2008, p. 303322.

STEWART-SYKES, A. From prophecy to preaching: a search for the origins of the Christian homily. Leiden: Brill, 2001.

TABBERNEE, W. Fake prophecy and polluted sacraments: ecclesiastical and imperial reactions to montanism. Leiden: Brill, 2007.

TORJESEN, K. J. Clergy and Laity. In: HARVEY, S. A.; HUNTER, D. G. (ed). The Oxford Handbook of Early Christian Studies. Oxford: Oxford University Press, 2008, p. 389-405.

TREBILCO, P. The Early Christians in Ephesus from Paul to Ignatius. Grand Rapids: William B. Eerdmans, 2004.

VAN DAM, R. The East (1): Greece and Asia Minor. In: HARVEY, S. A.; HUNTER, D. G. (ed.). The Oxford Handbook of Early Christian Studies. Oxford: Oxford University Press, 2008, p. 323-343.

VIVIANO, B. T. O Evangelho Segundo Mateus. In: BROWN, R. E.; FITZMYER, J. A.; MURPHY, R. E. (org.). Novo comentário bíblico São Jerônimo: Novo Testamento e artigos sistemáticos. São Paulo: Paulus, 2011, p. 131-216.

YARBRO COLLINS, A. Apocalipse. In: BROWN, R. E.; FITZMYER, J. A.; MURPHY, R. E. (org.). Novo comentário bíblico São Jerônimo: Novo Testamento e artigos sistemáticos. São Paulo: Paulus, 2011. 